\section{Prevalence of weight-loss strategies and use of substances for weight-loss among adults: a population study}

\author{
Prevalência de estratégias de emagrecimento e \\ uso de substâncias para perder peso entre \\ adultos: um estudo populacional
}

\author{
1 Universidade Federal de \\ Pelotas, Pelotas, Brasil. \\ Correspondence \\ E. C. Machado \\ Universidade Federal de \\ Pelotas. \\ Praça José Bonifácio 105, \\ apto. 301, Pelotas, $R S$ \\ 96015-170, Brasil. \\ eduardo.coelho.machado@ \\ gmail.com
}

\section{Abstract}

This paper concerns a cross-sectional population-based study conducted with adults living in the city of Pelotas, Rio Grande do Sul State. Brazil. It aims to determine the prevalence of weight-loss practices and use of substances for weight-loss during the 12 months preceding the interview. The prevalence of weight-loss attempts was 26.6\%. Although dietary control and regular physical exercise were the most commonly used strategies, the prevalence of the combined use of these methods was only $36 \%$ for individuals trying to lose weight. The prevalence of use of substances for weight-loss was 12.8\% (48.4\% of those who tried to lose weight). The use of dietary control and substances was more common among women, while men practiced physical exercise with greater frequency. Teas were the most frequently used substances for weight-loss. Multivariate analysis identified being female, excess weight and self-perception of excess weight as major associated factors for the use of substances for weight-loss. Finally, we found that, although weight-loss attempts are common, the majority of obese individuals do not make attempts to lose weight and only a minority follows the recommended practices.

Weight Loss; Anti-obesity Agents; Phytotherapy; Cross-Sectional Studies
Eduardo Coelho Machado 1

Mariângela Freitas da Silveira 1

Vera Maria Freitas da Silveira 1

\section{Introduction}

High prevalence of excess weight has been repeatedly documented in the literature 1,2 , mainly because of its strict relationship with several chronic diseases and risk of death 3,4 . In addition, overweight individuals suffer discrimination and stigma because of their appearance in a culture that excessively values a prototype of beauty associated with thinness, limiting the social and professional opportunities of those with this profile 5 .

Despite scientific interest and a proposal of the World Health Organization (WHO) in 2004 to create a set of strategies and goals to prevent obesity and chronic diseases 6 , the prevalence of obesity is increasing around the world. Recent data shows that $50 \%$ of the Brazilian adult population is overweight and $15 \%$ is obese 7 . International projections indicate that by 2015 , approximately 700 million people aged 15 years and over will be obese 8 . There is no sign that the pandemic is being controlled, indicating failures in the implementation of effective treatment and prevention strategies.

There is a consensus that lifestyle modification, such as healthy dietary habits and regular practice of physical activity 9,10, is necessary for long-term weight control. There are no highly efficacious and safe medicines for weight-loss 11 and, although there have been important surgical advances in this area, the use of this solution 
in the public health sector is limited due to contraindications and cost issues and should therefore be restricted to a limited sub-population 12 . Therefore, strategies besides lifestyle modification should be seen as complimentary.

Nonetheless, adherence to lifestyle modifications is low, as demonstrated by data from the $B e$ havioral Risk Factor Surveillance System (BRFSS) from 199613 and the National Health Interview Survey (NHIS) from 1998 14. Both studies indicate that while more than $30 \%$ of United States residents were attempting to lose weight, only 20 to $30 \%$ combined physical activity and dietary change in their strategy.

Despite clear evidence that modern lifestyles, increasing professional demands, the focus on technology and the influence of the media facilitate sedentary behavior and unhealthy dietary practices, it is possible that noncompliance with lifestyle modifications occurs partly because the effectiveness of this strategy does not match up to the individual's expectations 15 . Social pressure often demands improbable weight loss, thereby creating a highly favorable environment for unproven practices. The use of "alternative" treatments with no scientific foundation, that focuses on losing weight for aesthetic reasons and includes promises of rapid weight-loss without any effort, exposes individuals to dangerous substances that are ineffective (e.g.: teas, dietary supplements) 16,17 and hold possible health risks which are greater than their potential benefits (e.g.: weight-loss formulas, amphetamines) 18,19.

Although a widespread practice, the total extent of the use of substances for weight-loss in Brazilian society is unknown. The last 10 years has seen an absence of published population studies regarding the use of these substances, however, recent reports indicate that Brazil is a major consumer of weight-loss drugs 20,21 . In an article published in 1998, Lima et al. 22 found a $1.3 \%$ prevalence of amphetamine use among adults. International data, although scarce, suggests high consumption of substances for weightloss, which appears unaccompanied by adequate counseling and emphasis on lifestyle modification $23,24,25,26$.

The lack of Brazilian publications on this subject reinforces the need for contemporary studies regarding weight-loss practices among the population and associated characteristics. This knowledge is fundamental to better understand our reality, as well as to develop strategies to raise awareness regarding truly efficacious practices and the risks associated with unproven practices.

The goal of this work was to evaluate the prevalence of weight-loss strategies among the population during the 12 months that preceded the study, and identify the factors associated with the use of substances for weight-loss.

\section{Methods}

Between January and June of 2010, a cross-sectional population based study was conducted with adults aged 20 years and over residing in the urban zone of Pelotas, a municipality with approximately 350,000 inhabitants 27 , in Southern Brazil. The study united data collected through a series of projects undertaken by a consortium of different researchers using a common tool 28.

The multistage sampling process focused on sectors of the municipality taken from the 2000 demographic census, stratified by income. The necessary sample size was calculated for an estimated $11 \%$ prevalence of the use of substances for weight loss, with an acceptable error of 1.5 percentage points based on an unpublished study of weight-loss practices conducted in same city in 1999. The lowest prevalence ratio estimate for associations was 2.0 with a power of $80 \%$ and $95 \%$ confidence level. The study design effect was estimated at $50 \%$. The needed sample size was calculated as 2,656 individuals.

Sectors and households were randomly selected and all resident adults that did not meet exclusion criteria (non-Portuguese speaker, institutionalized person, physical or mental incapacity to answer questions) were invited to participate.

Questionnaires were administered using personal digital assistants (PDAs). Anthropometric measurements (weight and height) were taken of all eligible individuals that were able to stand. Data was collected by interviewers and anthropometrists trained on standard practices proposed by Lohman et al. 29 and Habitch 30 .

Use of substances for weight-loss was defined as the use of any medication (tea, herbs, natural remedy, nutritional supplements or other substance) with the aim of weight loss over the preceding 12 months reported by answering yes to the question: "have you done or used something to lose weight in the last year?". Those individuals that answered yes were asked specific questions about the use of each particular method (diet, exercise, medicines, teas, shakes, etc.).

The following independent variables were analyzed:

- Demographic: sex, age, observed skin color and marital status;

- Socioeconomic: education level (number of years of schooling) and family income;

- Anthropometric: body mass index (BMI), calculated based on the measured weight and height 
and categorized according to the WHO definition of overweight and obesity (normal weight up to $24.9 \mathrm{~kg} / \mathrm{m}^{2}$, overweight 25.0 to $29.9 \mathrm{~kg} / \mathrm{m}^{2}$ and obese $>30.0 \mathrm{~kg} / \mathrm{m}^{2}$ );

- Behavioral: leisure time physical activity evaluated by the short version of the International Physical Activity Questionnaire (IPAQ) and tobacco use defined as at least one cigarette per day for at least a month;

- Self-perception variable: where the participant chose one of six alternatives for how they viewed their body weight (too skinny, skinny, normal, fat, very fat).

Data from the PDAs was transferred frequently to a central computer using the PENDRAGON forms manager program version 5.1 (Pendragon Software Corp., Buffalo Grove, USA), allowing for review and timely correction of inconsistencies and missing data. Anthropometric data were collected using printed questionnaires and entered in the program Epi Info 6.04 (Centers for Disease Control and Prevention, Atlanta, USA), with double entry and validation.

Data quality was evaluated for $11 \%$ of the participants using a simplified questionnaire administered by field coordinators.

Statistical analysis was performed using Stata 11.0 (Stata Corp., College Station, USA). A descriptive analysis of sample characteristics and weight-loss strategies, stratified by sex, was also carried out. The prevalence of use of substances for weight-loss and type of substance utilized were also evaluated in relation to gender. Factors associated with use of substances for weight-loss were analyzed using Poisson regression to estimate the prevalence ratio $(\mathrm{PR})$ and confidence intervals 31. Statistical significance of associations was evaluated using the Wald test of heterogeneity of trends, using a $\mathrm{p}$-value $<0.05$ for statistically significant associations. All variables were analyzed using this model regardless of the results of crude analysis. To control for confounding factors, a $\mathrm{p}$-value $\leq 0.2$ was selected to keep variables in the model. We used a three-level hierarchical model to perform the multivariate analysis, where each variable was adjusted to variables at the same and higher levels with each level consisting of the following variables: level one-demographic and socioeconomic variables (more distal); level two - BMI, level of leisure time physical activity, tobacco use; level three self-perception of body weight. All participants signed a voluntary informed consent form that informed them about the study and their rights. The project was approved by the Research Ethics Committee of the Medical School of the Federal University of Pelotas.

\section{Results}

A total of 2,732 individuals were interviewed, of which 2,448 were measured and weighed. Losses or refusals amounted to $10.7 \%$ for interviews and $19.1 \%$ for anthropometric measurements. Regarding the use of substances for weight-loss, the sample design effect was 1.2 and the intraclass correlation coefficient was 0.01 . For the use of a weight-loss strategy in the preceding 12 months, the Kappa coefficient was 0.56 .

The characteristics of the sample are presented in Table 1. The average age of participants was 46.1 years with a standard deviation (SD) of 17.0 years. The majority of the sample was female, white and had eight or less years of schooling. Overall, $39 \%$ of the sample had household incomes of was over 3.6 minimum wages. Although excess weight was identified in $62 \%$ $\left(\mathrm{BMI} \geq 25.0 \mathrm{~kg} / \mathrm{m}^{2}\right)$ of the sample, almost half of the individuals (49.3\%) perceived themselves to be normal weight. Insufficient leisure time physical activity was observed in $75.6 \%$ of the sample.

Table 1 also shows the prevalence of weightloss attempts according to sample characteristics. Some kind of weight-loss attempt in the last year was reported by $26.6 \%$ (95\%CI: $24.6-28.6$ ) of the sample. Higher prevalence of weight-loss strategies was observed among females (30.8\%; 95\%CI: 28.5-33.2), individuals aged between 30 and 39 years (31.9\%; 95\%CI: 27.0-36.7) and single people (29.8; 95\%CI: 26.0-33.6). There was a positive association between prevalence rates and education level, household income, BMI and self-perception of being overweight. A total of $41.5 \%$ of obese individuals and $60.6 \%$ of individuals that perceived themselves as very fat reported having attempted to lose weight over the last 12 months.

The strategies used by those who attempted weight-loss are demonstrated in Table 2. The most frequent practices were dietary control (70.3\%; 95\%CI: 67.0-73.7) and physical exercise (55.7\%; 95\%CI: 51.9-59.6). The combination of both these methods occurred in 36\% (95\%CI: 32.4-39.6) of cases. Among individuals that tried to lose weight, $48.4 \%$ (95\%CI: $44.3-52.5)$ used a substance, which is equivalent to $12.8 \%$ (95\%CI: 11.5-14.2) of the total sample. The most commonly used substances for weight-loss among men and women were teas, followed by drugs among women and nutritional supplements among men.

A comparison between the sexes revealed that practicing exercise to lose weight was more common among men ( 66.7 vs. $50.4 \%$; $p<0.001$ ), while more women reported using dietary control (74.1 vs. $62.6 \% ; \mathrm{p}=0.001)$ and use of substances (59.5 vs. $25.6 \%$; $<<0.001)$. 
Sample characteristics and prevalence of weight-loss attempts. Pelotas, Rio Grande do Sul State, Brazil, 2010 (N = 2,732).

\begin{tabular}{|c|c|c|c|}
\hline Variables & $n(\%)$ & Weight-loss attempts $(95 \% \mathrm{Cl})$ & $\mathrm{p}$-value \\
\hline Sex & & & $<0.001$ * \\
\hline Male & $1,151(42.1)$ & $20.7(17.8-23.6)$ & \\
\hline Female & $1,581(57.9)$ & $30.8(28.5-33.2)$ & \\
\hline Age (years) & & & $<0.001$ * \\
\hline 20-29 & $595(21.8)$ & $30.5(26.7-34.3)$ & \\
\hline $30-39$ & $462(16.9)$ & $31.9(27.0-36.7)$ & \\
\hline $40-49$ & $545(20.0)$ & $27.3(23.4-31.3)$ & \\
\hline $50-59$ & $495(18.1)$ & $28.7(24.8-32.6)$ & \\
\hline 60 or + & $635(23.2)$ & $16.7(13.7-19.7)$ & \\
\hline Skin color & & & 0.04 * \\
\hline White & $2,218(81.2)$ & $27.3(25.1-29.6)$ & \\
\hline Non-white & $513(18.8)$ & $23.0(19.6-26.4)$ & \\
\hline Marital status & & & $<0.001$ * \\
\hline With a partner & $1,606(58.8)$ & $27.0(24.4-29.5)$ & \\
\hline Single & $644(23.6)$ & $29.8(26.0-33.6)$ & \\
\hline Divorced & $234(8.5)$ & $26.9(20.6-33.2)$ & \\
\hline Widowed & $248(9.1)$ & $14.9(10.4-19.4)$ & \\
\hline Schooling (years) & & & $<0.001$ ** \\
\hline $0-4$ & $678(24.9)$ & $15.3(12.4-18.3)$ & \\
\hline $5-8$ & $773(28.3)$ & $24.0(20.5-27.5)$ & \\
\hline $9-11$ & $732(26.8)$ & $30.6(27.3-33.9)$ & \\
\hline 12 or + & $547(20.0)$ & $38.6(34.7-42.5)$ & \\
\hline Family income (terciles) & & & $<0.001$ ** \\
\hline Lower & $742(27.4)$ & $20.7(17.5-23.9)$ & \\
\hline Medium & $907(33.6)$ & $23.4(20.5-26.2)$ & \\
\hline Higher & $1,054(39.0)$ & $33.4(30.4-36.4)$ & \\
\hline Current tobacco use & & & $<0.001$ * \\
\hline No & $2,149(78.7)$ & $29.5(27.2-31.8)$ & \\
\hline Yes & $583(21.3)$ & $15.6(12.5-18.8)$ & \\
\hline Self-perception of weight & & & $<0.001$ ** \\
\hline Very skinny/Skinny & $286(10.5)$ & $4.9(2.4-7.4)$ & \\
\hline Normal & $1,338(49.3)$ & $17.9(15.4-20.5)$ & \\
\hline Fat & $958(35.3)$ & $40.6(37.1-44.1)$ & \\
\hline Very fat & $133(4.9)$ & $60.6(51.8-69.4)$ & \\
\hline $\mathrm{BMI} \star \star \star$ & & & $<0.001$ ** \\
\hline Normal & $922(37.7)$ & $14.3(11.7-16.8)$ & \\
\hline Overweight & $888(36.3)$ & $29.9(26.3-33.6)$ & \\
\hline Obese & $638(26.0)$ & $41.5(37.7-45.3)$ & \\
\hline Leisure physical activity (IPAQ) & & & $<0.001$ * \\
\hline Insufficiently active & $2,007(75.6)$ & $24.7(22.5-26.9)$ & \\
\hline Active & $649(24.4)$ & $34.0(30.2-37.7)$ & \\
\hline
\end{tabular}

BMI: body mass index; IPAQ: International Physical Activity Questionnaire; 95\%Cl: $95 \%$ confidence interval.

* Chi-square test of heterogeneity;

** Chi-square test for trends;

$\star \star \star$ Variable with most number of unknowns (284), equivalent to $10.4 \%$. 
Weight-loss strategies adopted by those who attempted weight-loss in the last year according to gender. Pelotas, Rio Grande do Sul State, Brazil, 2010.

\begin{tabular}{|c|c|c|c|c|c|c|}
\hline & \multirow[t]{2}{*}{$\%(95 \% \mathrm{Cl})$} & \multicolumn{2}{|c|}{ Women $(n=487)$} & \multicolumn{2}{|c|}{ Men $(n=238)$} & \multirow[t]{2}{*}{$p$-value * } \\
\hline & & $\mathrm{n}$ & $\%(95 \% \mathrm{Cl})$ & $\mathrm{n}$ & $\%(95 \% \mathrm{Cl})$ & \\
\hline Change in diet & $70.3(67.0-73.7)$ & 361 & $74.1(69.9-78.4)$ & 149 & $62.6(56.8-68.4)$ & 0.001 \\
\hline Physical exercise & $55.7(51.9-59.6)$ & 245 & $50.4(45.6-55.3)$ & 158 & $66.7(60.4-73.0)$ & $<0.001$ \\
\hline Diet + exercise (combined) & $36.0(32.4-39.6)$ & 181 & $37.2(32.7-41.7)$ & 80 & $33.6(27.5-39.7)$ & 0.3 \\
\hline Use of some substance ** & $48.4(44.3-52.5)$ & 290 & $59.5(54.5-64.6)$ & 61 & $25.6(19.9-31.4)$ & $<0.001$ \\
\hline Teas & $32.8(28.6-37.0)$ & 203 & $41.8(36.3-47.2)$ & 34 & $14.4(9.7-19.0)$ & $<0.001$ \\
\hline Nutritional supplements & $15.6(13.1-18.1)$ & 92 & $18.9(15.7-22.1)$ & 21 & $8.8(5.6-12.0)$ & $<0.001$ \\
\hline Medicines & $18.1(15.3-20.8)$ & 114 & $23.4(19.7-27.1)$ & 17 & $7.1(3.6-10.7)$ & $<0.001$ \\
\hline Use of 2 or more types of substances & $15.7(13.1-18.3)$ & 101 & $20.9(17.3-24.6)$ & 11 & $5.0(2.0-8.1)$ & $<0.001$ \\
\hline
\end{tabular}

95\% Cl: 95\% confidence interval.

* Chi-square test of heterogeneity;

** Defined as any drug, tea, phytotherapy or nutritional supplement used for weight loss.

Note: Confidence intervals were measured considering the effect from the sample design.

Regarding BMI, weight-loss attempts in the last 12 months was more common among obese people (41.5\%; $95 \%$ CI: $37.7-45.3)$, as were dietary modifications (29.6\%; 95\%CI: 26.5-32.8) and physical exercise (20.9\%; 95\%CI: 17.8-24.0). The combination of both practices was reported by $14.2 \%$ (95\%CI: $11.5-16.8$ ) of obese individuals and $11 \%$ (95\%CI: 8.9-13.2) of overweight people. The prevalence of weight-loss attempts and the strategies utilized by the study population according to BMI are presented in Figure 1.

Usage of all weight-loss substances was greater among women (Figure 2). Use of teas was reported by $8.7 \%$ (95\%CI: 7.5-9.9) of the population and was the most commonly used substance by women and men. Weight-loss drugs were utilized by $7.3 \%$ (95\%CI: 6.0-8.6) of women and $1.5 \%$ (95\%CI: $0.7-2.2)$ of men.

Table 3 shows crude and adjusted analysis of factors associated with use of substances for weight loss, according to the hierarchical model. In the crude analysis, women younger than 40 years of age, with more than 11 years of schooling and increased family income, were more likely to use substances. Regarding self-perceived weight, $42.9 \%$ of those who perceived themselves as very fat and $24.3 \%$ of obese people used some kind of weight-loss substance.

In the adjusted analysis, being female and obese were the strongest predictors of the use of a substance for weight loss. Women were 3.48 (95\%CI: 2.59-4.68) times more likely than men to use some kind of substance. Among obese individuals PR was 5.31 (95\%CI: 3.93-7.18) times greater than in normal weight individuals. High- er prevalence of the use of substances for weightloss was also found among individuals younger than 60 years of age, with more than 4 years of schooling, increased family income and that perceived themselves as fat or very fat. In contrast, even after adjustment, smoking was associated with decreased use of substances for weight-loss (PR $=0.68$; 95\%CI: 0.50-0.93).

\section{Discussion}

Despite their importance, weight-loss strategies have not been studied at a population level in Brazil. For the first time, this study shows high prevalence of weight-loss practices and use of substances for weight-loss among a sample of the Brazilian adult population.

The observed frequency of weight-loss practices was similar to that reported more than 10 years ago in the US by Serdula et al. 13. Prevalence was less than that identified by Weiss et al. 32, using National Health and Nutrition Examination Survey (NHANES) data in 2002, than that observed in a Malaysian study carried out by Kong et al. ${ }^{24}$ and that found by Kruger et al. 14 in a study involving the NHIS in 1998.

Our data indicates that the pursuit of weightloss is frequently not combined with healthy practices. This observation is similar findings of Kruger et al. 14 in the US, where slightly more than $1 / 3$ of individuals who tried to lose weight in the previous year reported a combination of diet modification and physical activity. However, the fact that it is widely known that physical 
Figure 1

Prevalence of weight-loss attempts and strategies used for reducing weight during the last year, according to current body mass index (BMI). Pelotas, Rio Grande do Sul State, Brazil, 2010.

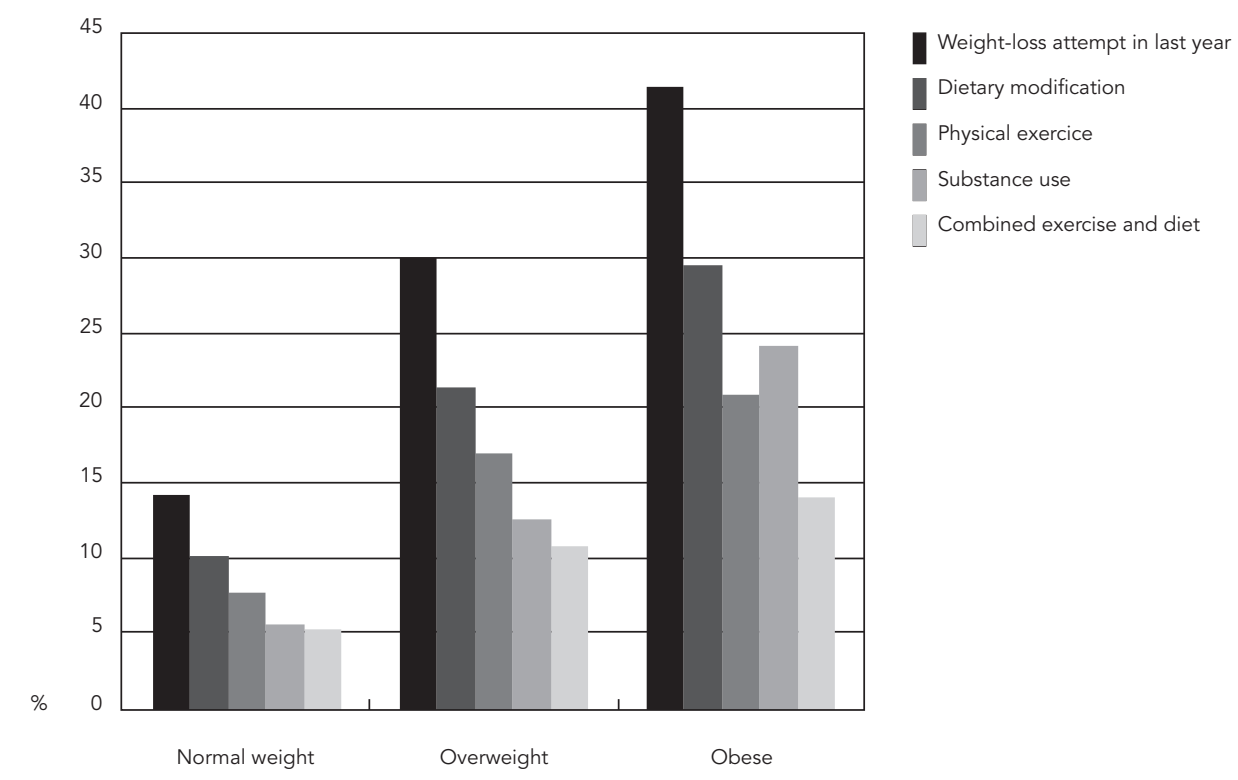

Figure 2

Prevalence of substances used for weight loss in the population, according to gender. Pelotas, Rio Grande do Sul State, Brazil, 2010.

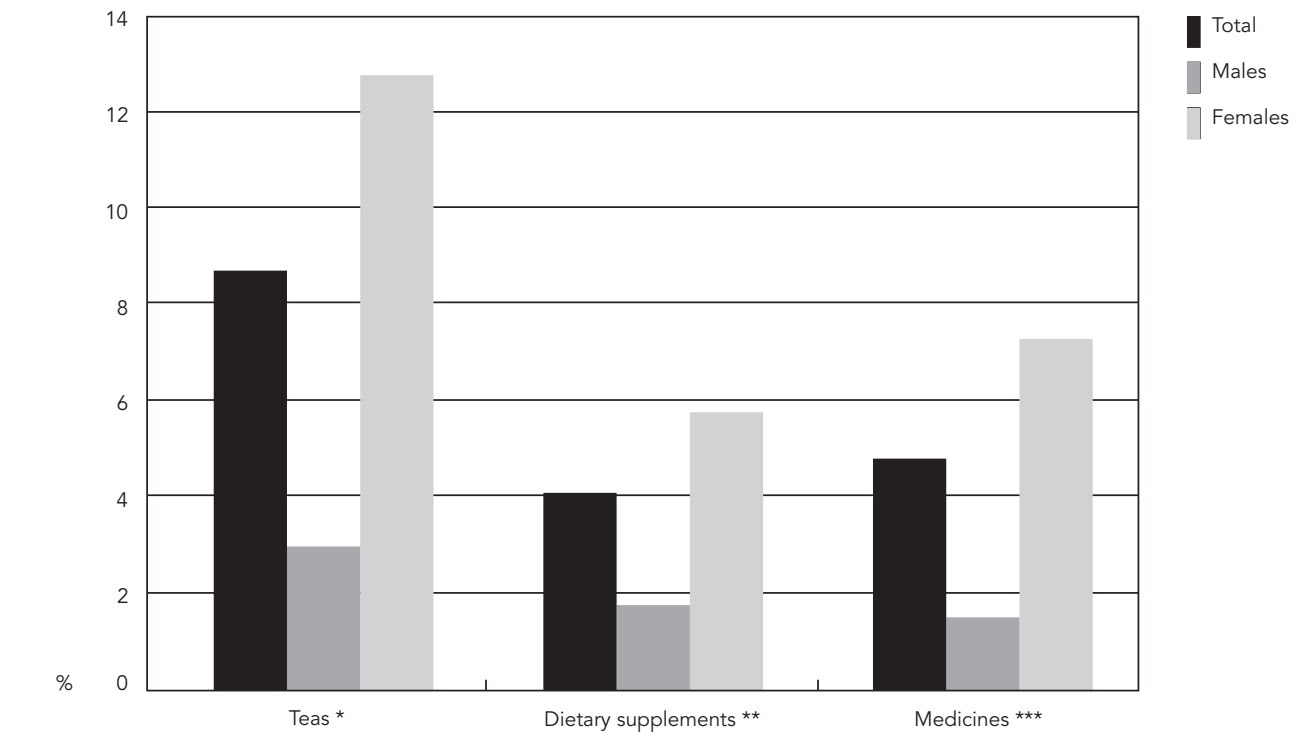

${ }^{*} p<0.001 ;{ }^{* \star} p<0.001 ;{ }^{* \star \star} p<0.001$ 
Factors associated with the use of substances for weight-loss -crude and adjusted analysis. Pelotas, Rio Grande do Sul State, Brazil, 2010 (N = 2,732).

\begin{tabular}{|c|c|c|c|c|c|c|}
\hline \multirow[t]{2}{*}{ Level * } & \multirow[t]{2}{*}{ Variables } & \multirow[t]{2}{*}{ Prevalence $(95 \% \mathrm{Cl})$} & \multicolumn{2}{|c|}{ Crude analysis } & \multicolumn{2}{|c|}{ Adjusted analysis } \\
\hline & & & PR $(95 \% \mathrm{Cl})$ & $p$-value & PR $(95 \% \mathrm{Cl})$ & p-value \\
\hline \multirow[t]{26}{*}{1} & Sex & & & $<0.001$ ** & & $<0.001$ ** \\
\hline & Male & $5.3(3.9-6.7)$ & 1.00 & & 1.00 & \\
\hline & Female & $18.3(16.2-20.5)$ & $3.46(2.59-4.63)$ & & $3.48(2.59-4.68)$ & \\
\hline & Age (years) & & & $<0.001 * \star$ & & $<0.001$ ** \\
\hline & 20-29 & $16.1(13.0-19.3)$ & $2.77(1.90-4.03)$ & & $2.34(1.59-3.45)$ & \\
\hline & $30-39$ & $17.1(13.6-20.6)$ & $2.93(1.93-4.46)$ & & $2.72(1.79-4.14)$ & \\
\hline & $40-49$ & $13.4(10.5-16.3)$ & $2.30(1.53-3.46)$ & & $2.23(1.47-3.38)$ & \\
\hline & $50-59$ & $13.3(10.3-16.4)$ & $2.29(1.57-3.34)$ & & $2.20(1.51-3.21)$ & \\
\hline & 60 or + & $5.8(3.9-7.8)$ & 1.00 & & 1.00 & \\
\hline & Skin color & & & $0.5^{* \star}$ & & $0.5^{\star \star}$ \\
\hline & Non-white & $12.1(11.5-14.5)$ & 1.00 & & 1.00 & \\
\hline & White & $13.0(9.2-14.9)$ & $1.08(0.84-1.38)$ & & $0.93(0.74-1.18)$ & \\
\hline & Marital status & & & 0.02 ** & & $0.7^{\star \star}$ \\
\hline & With a partner & $12.5(10.8-14.1)$ & $1.72(1.16-3.44)$ & & $1.26(0.80-2.00)$ & \\
\hline & Single & $15.4(12.7-18.1)$ & $2.12(1.31-3.42)$ & & $1.27(0.77-2.09)$ & \\
\hline & Divorced & $14.5(9.8-19.3)$ & $2.00(1.16-3.44)$ & & $1.39(0.80-2.42)$ & \\
\hline & Widowed & $7.3(4.1-10.5)$ & 1.00 & & 1.00 & \\
\hline & Schooling (years) & & & $<0.001 * \star \star$ & & $0.02 * \star \star$ \\
\hline & $0-4$ & $6.5(4.5-8.5)$ & 1.00 & & 1.00 & \\
\hline & $5-8$ & $12.7(10.1-15.2)$ & $1.95(1.34-2.85)$ & & $1.60(1.09-2.34)$ & \\
\hline & $9-11$ & $14.5(11.9-17.1)$ & $2.23(1.57-3.17)$ & & $1.56(1.09-2.24)$ & \\
\hline & 12 or + & $18.7(15.9-17.1)$ & $2.87(2.00-4.14)$ & & $1.74(1.15-2.65)$ & \\
\hline & Family income (terciles) & & & $<0.001$ *** & & $0.007^{\star \star \star}$ \\
\hline & Lower & $9.8(7.7-12.0)$ & 1.00 & & 1.00 & \\
\hline & Medium & $11.5(9.3-13.6)$ & $1.17(0.88-1.55)$ & & $1.16(0.88-1.53)$ & \\
\hline & Higher & $16.3(14.0-18.6)$ & $1.66(1.29-2.14)$ & & $1.50(1.12-2.02)$ & \\
\hline \multirow[t]{10}{*}{2} & Current tobacco use & & & $<0.001 \star \star$ & & 0.02 ** \\
\hline & No & $14.2(12.6-15.9)$ & 1.00 & & 1.00 & \\
\hline & Yes & $7.7(5.7-9.8)$ & $0.54(0.41-0.72)$ & & $0.68(0.50-0.93)$ & \\
\hline & $\mathrm{BMI}\left(\mathrm{kg} / \mathrm{m}^{2}\right)$ & & & $<0.001$ *** & & $<0.001 * \star \star$ \\
\hline & $<25.0$ (normal weight) & $5.7(4.1-7.4)$ & 1.00 & & 1.00 & \\
\hline & 25.0-29.9 (overweight) & $12.7(10.5-15.0)$ & $2.21(1.59-3.08)$ & & $3.08(2.26-4.18)$ & \\
\hline & $\geq 30.0$ (obese) & $24.3(20.9-27.7)$ & $4.23(3.03-5.90)$ & & $5.31(3.93-7.18)$ & \\
\hline & $\begin{array}{l}\text { Leisure time physical } \\
\text { activity (IPAQ) }\end{array}$ & & & 1.0 ** & & 0.8 ** \\
\hline & Insufficiently active & $13.2(11.4-14.9)$ & 1.00 & & 1.00 & \\
\hline & Active & $13.3(10.8-15.7)$ & $1.01(0.80-1.27)$ & & $1.03(0.80-1.32)$ & \\
\hline \multirow[t]{5}{*}{3} & $\begin{array}{l}\text { Self-perceived body } \\
\text { weight }\end{array}$ & & & $<0.001 * \star *$ & & $<0.001$ *** \\
\hline & Very skinny/Skinny & $0.7(0.03-1.7)$ & $0.11(0.03-0.43)$ & & $0.15(0.04-0.60)$ & \\
\hline & Normal & $6.5(5.1-7.9)$ & 1.00 & & 1.00 & \\
\hline & Fat & $21.4(18.5-24.3)$ & $3.29(2.55-4.24)$ & & $2.11(1.52-2.91)$ & \\
\hline & Very fat & 42.9 (34.4-51.4) & $6.59(4.89-8.88)$ & & $3.30(2.26-4.81)$ & \\
\hline
\end{tabular}

BMI: body mass index; IPAQ: International Physical Activity Questionnaire; PR: prevalence ratio; $95 \% \mathrm{Cl}$ : 95\% confidence interval.

* Level of the variable according to the hierarchical analysis model. The measure of effect is controlled for all the variables of the same level or higher levels that present a p-value $<0.2$;

$\star \star$ Wald test of heterogeneity;

$\star \star *$ Wald test for trends. 
activity is a healthy practice may have induced some individuals to choose this answer. We can therefore assume that physical activity is less common than reported and that the data overestimates prevalence 33 .

Lifestyle modifications are essential and are universally recommended in the treatment of overweight individuals 34,35 . The study found that less than $30 \%$ of overweight individuals and more than $40 \%$ of obese people reported a weight-loss attempt in the last year. Although weight-loss strategies are more prevalent in these subgroups than among groups with appropriate weight, the combination of healthy practices was the exception and was reported by less than $15 \%$ of these individuals. Although obesity may limit physical activity and the frequency of combined health practices, it seems that even those individuals who most need to lose weight tend to opt for inadequate strategies whose use is based on low levels of scientific evidence.

Gender differences were found with respect to weight-loss strategy. As reported by other studies 13,14,36, weight-loss attempts and consumption of substances for diet and weight-loss were greater in women. In contrast to Serdula et al. 13, that reported equal use of physical activity by men and women as a weight-loss strategy, in our study men used physical activity more often to lose weight.

Regarding the consumption of substances for weight-loss, the observed prevalence differed from findings of other population studies. It should be noted that the prevalence of obesity and the variety of cultural characteristics between different populations may significantly influence this practice and no comparable Brazilian studies were identified on this subject. However, international publications show that use of substances for weight-loss varies between $4 \%$, in the NHIS study of 1998 14, and 33.9\%, reported in a study undertaken by Pilliteri et al. 26 which had a $19 \%$ response rate. Another study in the US with high refusal rates 25 found a prevalence of $8.7 \%$ for the use of non-prescribed substances during the preceding year.

Teas were the most common weight-loss substances consumed in our sample, among both men and women. Nonetheless, few publications evaluate the use of these substances at the population level. Blank et al. 23 and a Malaysian study carried out by Konget al. 24, showed that approximately $10 \%$ of adults used some herbal product for weight loss. Also, the National Physical Activity and Weight-loss Survey in 2002 25, found a higher than $15 \%$ prevalence rate.

It is interesting to note that when we evaluated herbal supplements, there were no usage indications for the treatment of excess weight and no scientific evidence that these methods are effective 17,37,38. Indeed, several publications suggest potentially harmful effects of these substances, especially gastrointestinal and psychological disorders and hepatic lesions 39,40.

In accordance with other studies $23,35,41$, we found an association between use of substances for weight-loss and being female and overweight. The consistency of these findings reinforces the idea that both characteristics are undeniably associated with use of weight-loss substances and are the strongest predictors of this behavior.

In relation to age, there was an increased likelihood of use of substances for weight-loss in people younger than 60 years of age, regardless of sex. This finding is similar to that observed by Kruger et al. 14. However, other publications found an association only in younger age groups 36,42 .

Skin color and marital status were not associated with use of substances or weight-loss practices. Although some US publications 26,41 report non-white skin color as a risk factor, it is likely that this finding is associated with the specific cultural characteristics of the population. In Brazil, skin color is not associated with weight-loss practices due to higher levels of cultural miscegenation and an increased diffusion of concern over body shape.

An inverse association with tobacco use was also identified in other studies 13 , with evidence of increased risk of weight gain associated with tobacco cessation 43 . This finding may reflect the belief that smoking could work as a weight control strategy 44 and demonstrates the emphasis on the aesthetic aspects of weight loss, irrespective of the health implications. Furthermore, the lower prevalence of weight-loss attempts in obese smokers than in obese nonsmokers $(44.1 \%$ vs. $27.7 \%$ ) could be an indication of worse general health-care associated with smoking, as has been demonstrated in other studies 45 .

Self-perceived excess weight was a factor independently associated with use of substances for weight loss. No publication regarding this specific association was identified, but studies with adolescents have found increased risk of weight-loss practices 46,47 and unhealthy weightloss strategies 48,49 associated with self-perception of excess weight.

Our study has certain limitations. The crosssectional design hampers the evaluation of causality for some associations. Prevalence of 5.4\% for substance use in the subgroup with normal BMI could reflect the effectiveness of the treatment, where previously obese individuals may have normalized their weight due to the use of 
the reported substance. This possibility is unlikely however, since the vast majority of substances for weight-loss do not show substantial ability to reduce body weight and therefore normalize the BMI of an obese person.

The causal association with physical activity may also be biased due to reverse causality. However, no evidence was found for this, since the prevalence of physical activity and reports of physical activity were similar between users and non-users of substances for weight-loss. The most relevant finding was the high prevalence ( $>75 \%$ ) of sedentary behavior among users of weight-loss supplements.

One of the strong points of this study is that the response rate is the highest among the identified publications with similar objectives 13,14,23,25,26. The greater frequency of men among losses may lead to an overestimate of the frequency of weight-loss strategies and use of substances. However, this does not appear to have influenced the estimates of association, and effect modification associated with gender was not found.

\section{Resumo}

Estudo transversal de base populacional conduzido com adultos residentes na cidade de Pelotas, Rio Grande do Sul, Brasil, que objetivou determinar a prevalência de práticas de emagrecimento e uso de substâncias para emagrecer, nos últimos 12 meses antes da entrevista. A prevalência de tentativas de emagrecimento foi de 26,6\%. Controle dietético e prática regular de exercícios físicos foram as estratégias mais frequentes, mas apenas $36 \%$ daqueles que tentaram emagrecer combinaram-nas. A prevalência do uso de substâncias para emagrecer foi de 12,8\% (48,4\% daqueles que tentaram emagrecer). Mulheres utilizaram controle dietético e substâncias mais frequentemente do que homens, enquanto estes utilizaram mais exercícios físicos. As substâncias de uso mais frequente foram os chás. A análise ajustada identificou sexo feminino, excesso de peso e percepção do excesso de peso como os maiores fatores associados ao uso de substâncias. Assim, identificamos que tentativas de emagrecimento são frequentes, porém, não são referidas pela maioria dos obesos e apenas uma minoria daqueles que tentam emagrecer segue as práticas recomendadas.

Perda de Peso; Fármacos Antiobesidade; Fitoterapia; Estudos Transversais
Our findings reinforce the idea that, although weight-loss attempts and use of substances for weight-loss are common practices, these strategies are not used by the majority of individuals that need to lose weight. The fact that most individuals who attempt to lose weight do not adhere to recommended practices, may reflect the aesthetic emphasis of weight-loss strategies. In addition, the high usage of unproven substances with potentially adverse effects reveals the need for greater control of teas, phytotherapies and dietary supplement sales, and highlights the importance of awareness raising actions concerning the lack of efficacy and risk of these methods.

Finally, the findings show that the issue of "weight loss" is extremely prominent and important in our society, and there is a public health need to spread clear information about the risks associated with certain weight-loss practices and emphasize the necessity to create public policies to promote lifestyle modification and the regulation of substances with unproven efficacy and safety.

\section{Contributors}

E. C. Machado participated in all stages of the study, including conception and design, acquisition, analysis and interpretation of data and drafting this article. M. F. Silveira and V. M. F. Silveira participated in the conception and design of the study, data interpretation and critical revision of this article.

\section{Acknowledgments}

This study was fully supported by the Post-graduate Program in Epidemiology of Federal University of Pelotas (Programa de Pós-graduação em Epidemiologia; Universidade Federal de Pelotas), with resources from the CAPES. 


\section{References}

1. Caballero B. The global epidemic of obesity: an overview. Epidemiol Rev 2007; 29:1-5.

2. Prentice AM. The emerging epidemic of obesity in developing countries. Int J Epidemiol 2006; 35:93-9.

3. Overweight, obesity, and health risk. National Task Force on the Prevention and Treatment of Obesity. Arch Intern Med 2000; 160:898-904.

4. Nguyen NT, Magno CP, Lane KT, Hinojosa MW, Lane JS. Association of hypertension, diabetes, dyslipidemia, and metabolic syndrome with obesity: findings from the National Health and Nutrition Examination Survey, 1999 to 2004. J Am Coll Surg 2008; 207:928-34.

5. Carr D, Friedman MA. Is obesity stigmatizing? Body weight, perceived discrimination, and psychological well-being in the United States. J Health Soc Behav 2005; 46:244-59.

6. Waxman A. WHO global strategy on diet, physical activity and health. Food Nutr Bull 2004; 25: 292-302.

7. Instituto Brasileiro de Geografia e Estatística. Pesquisa de Orçamentos Familiares - POF 2008-2009. Antropometria e estado nutricional de crianças, adolescentes e adultos no Brasil. Brasília: Instituto Brasileiro de Geografia e Estatística; 2010.

8. World Health Organization. Fact sheet no. 311: obesity and overweight. Geneva: World Health Organization; 2006.

9. Wilding JP. Treatment strategies for obesity. Obes Rev 2007; 8 Suppl 1:137-44.

10. Rao G. Office-based strategies for the management of obesity. Am Fam Physician 2010; 81:1449-56.

11. Padwal R, Li SK, Lau DC. Long-term pharmacotherapy for obesity and overweight. Cochrane Database Syst Rev 2004; CD004094.

12. Colquitt JL, Picot J, Loveman E, Clegg AJ. Surgery for obesity. Cochrane Database Syst Rev 2009; CD003641.

13. Serdula MK, Mokdad AH, Williamson DF, Galuska DA, Mendlein JM, Heath GW. Prevalence of attempting weight-loss and strategies for controlling weight. JAMA 1999; 282:1353-8.

14. Kruger J, Galuska DA, Serdula MK, Jones DA. Attempting to lose weight: specific practices among U.S. adults. Am J Prev Med 2004; 26:402-6.

15. Polivy J. The false hope syndrome: unrealistic expectations of self-change. Int J Obes Relat Metab Disord 2001; 25 Suppl 1:S80-4.

16. Lenz TL, Hamilton WR. Supplemental products used for weight loss. J Am Pharm Assoc (2003) 2004; 44:59-67.

17. Pittler MH, Ernst E. Complementary therapies for reducing body weight: a systematic review. Int J Obes (Lond) 2005; 29:1030-8.

18. Kaptein EM, Beale E, Chan LS. Thyroid hormone therapy for obesity and nonthyroidal illnesses: a systematic review. J Clin Endocrinol Metab 2009; 94:3663-75.

19. Singleton J, Degenhardt L, Hall W, Zabransky T. Mortality among amphetamine users: a systematic review of cohort studies. Drug Alcohol Depend 2009; 105:1-8.
20. Informe de la Junta Internacional de Fiscalización de Estupefacientes. New York: Naciones Unidas; 2010.

21. United Nations Office on Drugs and Crime. 2008 World Drug Report. Vienna: United Nations; 2008.

22. de Lima MS, Beria JU, Tomasi E, Mari JJ. Use of amphetamine-like appetite suppressants: a crosssectional survey in Southern Brazil. Subst Use Misuse 1998; 33:1711-9.

23. Blanck HM, Khan LK, Serdula MK. Use of nonprescription weight-loss products: results from a multistate survey. JAMA 2001; 286:930-5.

24. Kong WT, Chua SS, Alwi S. Weight-loss practices among Malaysian adults. Asia Pac J Public Health 2002; 14:99-104.

25. Blanck HM, Serdula MK, Gillespie C, Galuska DA, Sharpe PA, Conway JM, et al. Use of nonprescription dietary supplements for weight-loss is common among Americans. J Am Diet Assoc 2007; 107:441-7.

26. Pillitteri JL, Shiffman S, Rohay JM, Harkins AM, Burton SL, Wadden TA. Use of dietary supplements for weight-loss in the United States: results of a national survey. Obesity (Silver Spring) 2008; 16:790-6.

27. Instituto Brasileiro de Geografia e Estatística. Estimativa populacional para 2009 - Pelotas, RS. http://www.ibge.gov.br/cidadesat/topwindow. htm?1.

28. Barros AJ, Menezes AMB, Santos IS, Assunção MCF, Gigante D, Fassa AG, et al. UFPel's epidemiology MSc program based on research consortium: an innovative experience. Rev Bras Epidemiol 2008; 11 Suppl 1:133-44.

29. Lohman TG, Roche AF, Martorell R. Anthropometric standardization reference manual. Champaign: Human Kinetics Books; 1988.

30. Habicht JP. Standardization of quantitative epidemiological methods in the field. Bol Oficina Sanit Panam 1974; 76:375-84.

31. Barros AJ, Hirakata VN. Alternatives for logistic regression in cross-sectional studies: an empirical comparison of models that directly estimate the prevalence ratio. BMC Med Res Methodol 2003; $3: 21$.

32. Weiss EC, Galuska DA, Khan LK, Serdula MK. Weight-control practices among U.S. adults, 20012002. Am J Prev Med 2006; 31:18-24.

33. Knuth AG, Bielemann RM, Silva SG, Borges TT, Del Duca GF, Kremer MM, et al. Conhecimento de adultos sobre o papel da atividade física na prevenção e tratamento de diabetes e hipertensão: estudo de base populacional no Sul do Brasil. Cad Saúde Pública 2009; 25:513-20.

34. Tsigos C, Hainer V, Basdevant A, Finer N, Fried M, Mathus-Vliegen E, et al. Management of obesity in adults: European clinical practice guidelines. Obes Facts 2008; 1:106-16.

35. Cannon CP, Kumar A. Treatment of overweight and obesity: lifestyle, pharmacologic, and surgical options. Clin Cornerstone 2009; 9:55-68. 
36. Bendixen H, Madsen J, Bay-Hansen D, Boesen U, Ovesen LF, Bartels EM, et al. An observational study of slimming behavior in Denmark in 1992 and 1998. Obes Res 2002; 10:911-22.

37. Pittler MH, Ernst E. Dietary supplements for bodyweight reduction: a systematic review. Am J Clin Nutr 2004; 79:529-36.

38. Egras AM, Hamilton WR, Lenz TL, Monaghan MS. An evidence-based review of fat modifying supplemental weight loss products. J Obes 2011; [Epub 2010 Aug 10].

39. Pittler MH, Schmidt K, Ernst E. Adverse events of herbal food supplements for body weight reduction: systematic review. Obes Rev 2005; 6:93-111.

40. Hasani-Ranjbar S, Nayebi N, Larijani B, Abdollahi M. A systematic review of the efficacy and safety of herbal medicines used in the treatment of obesity. World J Gastroenterol 2009; 15:3073-85.

41. Khan LK, Serdula MK, Bowman BA, Williamson DF. Use of prescription weight-loss pills among U.S. adults in 1996-1998. Ann Intern Med 2001; 134:282-6.

42. Levy AS, Heaton AW. Weight control practices of U.S. adults trying to lose weight. Ann Intern Med 1993; 119:661-6.
43. Chiolero A, Faeh D, Paccaud F, Cornuz J. Consequences of smoking for body weight, body fat distribution, and insulin resistance. Am J Clin Nutr 2008; 87:801-9.

44. Li MD, Kane JK, Konu O. Nicotine, body weight and potential implications in the treatment of obesity. Curr Top Med Chem 2003; 3:899-919.

45. Wolf R, Freedman D. Cigarette smoking, sexually transmitted diseases, and HIV/AIDS. Int J Dermatol 2000; 39:1-9.

46. Strauss RS. Self-reported weight status and dieting in a cross-sectional sample of young adolescents: National Health and Nutrition Examination Survey III. Arch Pediatr Adolesc Med 1999; 153:741-7.

47. Cheung PC, Ip PL, Lam ST, Bibby H. A study on body weight perception and weight control behaviours among adolescents in Hong Kong. Hong Kong Med J 2007; 13:16-21.

48. Wharton CM, Adams T, Hampl JS. Weight-loss practices and body weight perceptions among US college students. J Am Coll Health 2008; 56:579-84.

49. Harring HA, Montgomery K, Hardin J. Perceptions of body weight, weight management strategies, and depressive symptoms among US college students. J Am Coll Health 2010; 59:43-50.

Submitted on 22/Sep/2011

Final version resubmitted on 01/Mar/2012

Approved on 23/Mar/2012 